\title{
O RIO CAPITAL IMAGINADO PELA CRÍTICA CINEMATOGRÁFICA: os casos de Rio Fantasia e Rio, 40 graus
}

\author{
Eliska Altmann*
}

\begin{abstract}
No artigo, busca-se verificar como o Rio de Janeiro, "cidade-capital”, foi imaginado por críticos cinematográficos brasileiros. Por meio de críticas aos filmes Rio fantasia (1957), de Watson Macedo, e Rio, 40 graus (1955), de Nelson Pereira dos Santos, pretende-se entender como a então Capital Federal foi descrita e legitimada por agentes que formam julgamentos, quiçá, para a posteridade.

Palavras-Chave: Rio de Janeiro. Capitalidade. Cinema. Crítica cinematográfica.
\end{abstract}

\section{INTRODUÇÃO}

Uma cartografia com iconografias do Rio de Janeiro do século XIX nos remeteria a paisagens de montanhas, ilhas, baía, litoral, florestas, e também à urbanidade crescente. Tais caminhos, ao configurarem aspectos naturais e cenários sociais, viriam representar certa identidade de "cidade maravilhosa" e utópica, imagem do Brasil e símbolo da civilização. Tal visão, geralmente harmônica e idílica, foi traduzida em tintas por "imaginadores" (desbravadores e viajantes europeus), como Félix-Émile Taunay e Debret.

Nas telas daquele século constata-se que num primeiro momento, o que corresponde à chegada ao Brasil das Expedições Naturalistas e da Missão Francesa (1816), à fundação da Real Academia de Belas Artes (1820) e à fase da Regência (18311840), ganham evidência as representações de paisagens naturais e urbanas, cenas de fatos históricos e de costumes do Rio de Janeiro, somando-se a in-

* Universidade Federal Rural do Rio de Janeiro (UFRRJ). Departamento de Ciências Sociais. Programa de Pós-Graduação em Ciências Sociais (PPGCS).

BR-465, Km 7 Seropédica. Cep: 23.897-000. Rio de Janeiro

- Rio de Janeiro - Brasil. eliskaaltmann@gmail.com tenção estética à visão documental, propagandística e insólita da realidade [...] Quase sempre com a Baía de Guanabara a legitimar a contundente e exuberante paisagem tropical e seus signos mais representativos (na maioria das vezes, o Pão de Açúcar) [...] Na análise desses panoramas sobressaem alguns aspectos: primeiramente, a enorme extensão de espaço horizontal que ocupa a tela e que articula, em três faixas, o mar, a terra e o céu, numa tentativa de abarcar a Baía e a cidade. A seguir, a estrutura simples, mas bem delineada, da paisagem, sobretudo a terrestre, que corresponde à faixa intermediária, a urbana. Sem dúvida, uma visão bucólica, romântica, em que a natureza e o construído convivem numa atmosfera serena e luminosa (Carvalho, 2000, p. 41-45).

Enquanto "o registro [pictórico] sistemático da paisagem do Rio de Janeiro teve início a partir da abertura dos portos às nações amigas, em 1808" (Martins, 2000, p. 76), o cinematográfico viria ocorrer nove décadas depois. Contudo, diferentemente dos quadros e aquarelas, "infelizmente as centenas de filmes aqui realizados de 1898 a 1930 perderam-se quase todos" (Heffner, 2015, p. 12). Além de certa conservação do material, outra dessemelhança que poderia ser examinada na comparação entre os dois tipos de registro é um desencaixe em relação ao que queriam mostrar, posto que 
o cinema do início do século XX apresentaria atributos distanciados daquela atmosfera "serena e luminosa".

Diversamente às belas artes, nas primeiras fitas rodadas no Rio de Janeiro "nenhum cineasta ou cinegrafista carioca parece ter se preocupado em destacar ícones da beleza da cidade [...] Nas listagens de filmes que chegaram até nós, nada parece indicar a presença desse tipo de approach, ou seja, a cidade não é ainda apreciável, objeto definido e definível através de imagens enquadradas com intenções conscientes" (Heffner, 2015, p. 12-13). Signos urbanos, como a Avenida Central, foram temas de filmes e documentários das primeiras décadas do novo século, e signos paisagísticos, como o Pão de Açúcar, se tornaram cenário cinematográfico mais precisamente na década de 1920, que passou a englobar, isto sim, um projeto estético "turístico", de "embelezamento cinematográfico” (Heffner, 2015). ${ }^{1}$

Sobre a produção que se estende até a primeira década do século XX, Eduardo Morettin chama atenção para o que mostram as imagens produzidas no país, "uma vez que estão em pauta a ideologia da 'higienização' e a vontade de tornar o cinema uma dupla vitrine do progresso nacional” (Morettin, 2005, p. 135; 2012). O historiador aponta um "desajuste" entre o que é trazido pela imagem e desejado pelo S espectador. A tônica do controle almejado e ¿ instituído, tanto pelo Estado quanto pelo cam屯 po cinematográfico, teria se pautado no requisito da exibição de "imagens limpas, indicadoras de progresso e desenvolvimento. Brancura, ถิ decência e ingenuidade caminham juntas na $\stackrel{2}{i}$ exigência de uma imagem cinematográfica que $\infty$

${ }^{1}$ Para uma discussão mais aprofundada sobre a "primeira época” do cinema no Brasil, sua produção e circulação, no período que compreende a virada de século (até sua segunda década), ver Araújo (1976) e Souza (2004). Para um entendimento da historiografia no país, ver Gomes (1980) e Bernardet (2004).
15). Nas décadas subsequentes,

o tratamento da paisagem carioca seguirá duas grandes linhas. Uma se dedicará a apresentar a cidade de forma harmoniosa, recorrendo aos ícones como confirmação [...] A outra linha procurará justamente o confronto entre esse Rio cartão-postal e sua vivência cotidiana (Heffner, 2015, p. 17).

O resultado desse contraste seria a construção da figura do carioca, um "tipo" cujas relações sociais e culturais acontecem na "cidade maravilhosa” (Heffner, 2015). Contornos paisagísticos, Cristo Redentor e praias da Zona Sul passam a espelhar certo sentido de "ufanismo carioca”, contrastado com produções que encenam camadas populares, subúrbio, favelização e morros. Justamente desse confronto nasce a presente investigação, que consiste na análise de críticas ao filme Rio fantasia, representante da chanchada, ${ }^{2}$ a exaltar alegrias e belezas da capital, e ao "divisor de águas", Rio, 40 graus. ${ }^{3}$

Na tentativa de entender como a Capital Federal foi então imaginada pelo campo da crítica ${ }^{4}$, noto que ambas as produções - de 1955 e 1957 - foram realizadas e lançadas no processo de tomada de posse do presidente Juscelino Kubitschek, que

conseguiu transformar o Plano de Metas no projeto de um Brasil possível. Seu programa de governo dava voz a uma nova e entusiástica condição de ser brasileiro, que poderia contribuir para reparar as injustiças de uma herança histórica de miséria e desigualdades profundas, e serviria para abrir as portas da modernidade. A chave para construir esse

2 "Gênero de ampla aceitação popular que melhor sintetiza e define o cinema brasileiro das décadas de 30, 40 e, principalmente, 50 , produzido majoritariamente no Rio de Janeiro. A designação pejorativa, adotada por vários críticos de cinema, possui origem etimológica no italiano cianciata, que significa um discurso sem sentido, uma espécie de arremedo vulgar, argumento falso" (Vieira, 2000). Para uma discussão aprofundada sobre o tema, ver Vieira(1987), Souza e Catani (1983) e Dias (1993).

${ }^{3}$ Vale notar que os documentos pesquisados referem-se a duas representações antitéticas de urbanidade: a primeira, representante da chanchada e a segunda, (neo)realista, inspiradora do ideal estético do Cinema Novo.

${ }^{4}$ Para um debate sobre capitalidade e cinema brasileiro, ver, entre outros, Pinto (2011), Kornis (2003), Lobo (2011) e Melo (s/d). 
novo país chamava-se ‘desenvolvimentismo' e defendia a ideia de que a nossa sociedade, defasada e dependente dos países mais avançados, repartia-se em duas: uma parte do Brasil ainda era atrasada e tradicional; a outra já seria moderna e estava em franco desenvolvimento. Ambas, o centro e a periferia conviveriam no mesmo país, e essa era uma dualidade que se devia resolver pela industrialização e pela urbanização. (Schwarcz; Starling, 2015, p. 98).

Tal contexto envolve diretamente o Rio que, como capital, tinha a função de "representar a unidade e a síntese da nação" e o papel de "lócus da identidade nacional" ou "vitrine do país” (Motta, 2004). Desde a sua origem, como capital imperial,

além da matriz irradiadora da unidade e da ordem, a construção da capitalidade do Rio de Janeiro tinha outro pilar: o cosmopolitismo. A cidade era o principal elo com o mundo europeu, garantindo sua própria inserção no chamado processo civilizacional e se tornando a fonte de irradiação dessa civilização no país [...] Sede do governo nacional, era no Rio que ecoavam os debates no Parlamento e na imprensa. (Motta, 2004, p. 16-17). ${ }^{5}$

Com base nesse panorama, que tem uma importância peculiar "conferida aos símbolos, signos, práticas e valores” (Motta, 2004), apresento as sinopses dos dois filmes, que parecem parafrasear duas dimensões sociais (e ideológicas) acentuadas nos anos 1960: de um lado, o progresso e o desenvolvimentismo; do outro, sua inviabilidade, denunciada pelo subdesenvolvimento e sua necessidade de superação.

Em pesquisa realizada na Cinemateca do MAM (RJ), encontrei, junto ao cartaz de Rio fantasia, o seguinte argumento, publicado em 1957: "Quarteto de músicos nordestinos vai tentar a sorte no Rio de Janeiro. Com bom humor e muita música, eles enfrentam as dificuldades da cidade grande em busca do sucesso. Comédia musical". No acervo da Cinemateca Brasileira sobre o filme, ainda localizei o seguinte resumo: "O quarteto de Tacurumbiga (cidade do Nordeste) chega ao Rio de Janeiro em busca do sucesso. Hospeda-se na pensão

${ }^{5}$ Sobre o conceito de capitalidade (e Rio de Janeiro), ver também Azevedo (2002). de D. Amélia, que cobra as diárias atrasadas com um trabuco na mão. O quarteto resolve apresentar-se num espetáculo de caridade para ver se alguém os descobre. Na plateia, estão Freitas e Carlos, diretores geral e artístico da TV Rio, respectivamente. O primeiro se interessa por Lia e, no dia seguinte, convida-a para estrelar uma série de programas semanais em homenagem a Carmem Miranda. Infelizmente quer só ela, o resto do quarteto que se arranje".

Sobre o filme Rio, 40 graus, em documento oficial de divulgação e pesquisa da Embrafilme, pode-se ler a resenha:

Drama urbano. O filme é uma crônica da cidade do Rio de Janeiro, em um domingo de verão ensolarado, narrado através das peripécias de cinco pequenos vendedores de amendoim. Eles se dividem pelos diversos pontos característicos do Rio à procura do melhor mercado para seu produto. Em cada um desses locais, Copacabana, Pão de Açúcar, Corcovado, Quinta da Boa Vista e Maracanã, emerge um episódio típico da vida da população carioca.

Outro prospecto de divulgação, cujo titulo é "Um panorama fotográfico humano da cidade maravilhosa", apresenta a sinopse: "Um retrato de corpo inteiro da Cidade Maravilhosa, através do desenrolar das grandezas e da miséria de uma cidade grande. A tragédia e a poesia se misturam na sinfonia colorida da paisagem bela de um povo simples, sentimental, mas, por vezes, egoísta. Rio, 40 graus é um filme que imita a vida, e, como ela, não tem começo, não tem fim... é apenas um pedaço amargo arrancado ousadamente dos pequenos detalhes de um dia quente de verão" ${ }^{6}$

Ambos os cenários e contrastes não são contingentes. Símbolos de circunstâncias históricas e sociais, eles parecem encarnar as próprias transformações urbanas projetadas, sobretudo, no crescimento irrefreável, na migração (do campo para a cidade) e na industrialização, que configuram, em seu decurso, divisão de classes e suas consequências. Nesse

${ }^{6}$ O filme faz parte de uma trilogia que inclui Rio, Zona Norte (1957) e Rio, Zona Sul, nunca realizado. No lugar desse último, Nelson Pereira dos Santos realizou El Justicero (1967). 
contexto de modernização (tradicional) brasileira, o Rio de Janeiro passa a concentrar uma progressiva população, sem contar com infraestrutura nem oferta de empregos à altura.

De acordo com o pesquisador Júlio César Lobo (2006, p. 169),

a década brasileira de 1950 se inicia com o registro de uma forte migração em direção à ex-capital federal, São Paulo e Minas Gerais. Fixemo-nos apenas na também ex-Cidade Maravilhosa. Em sua área de influência, passam a residir naquele momento 191.917 mineiros, 55.746 capixabas, 46.990 paulistas, 45.157 pernambucanos, 44.936 baianos, 27.267 alagoanos, 23.209 paraibanos, 18.001 cearenses e 13.468 potiguares, entre outros. Curiosamente, os migrantes naturais de maior expressividade quantitativa no período na região da ex-capital federal - provenientes dos vizinhos estados de Minas Gerais, Espírito Santo e São Paulo - não se encontram caracterizados nas chanchadas da época, que privilegiam a caricatura de nordestinos.

Isto posto, meu interesse é desvendar como textos críticos avaliaram tal conjuntura através de Rio fantasia (1957) e Rio, 40 graus (1955). Portanto, cabe-me averiguar as matérias. Antes de abordar as críticas, contudo, considero necessário traçar as biografias de Watson Macedo e Nelson Pereira dos Santos, aqui entendidos como cronistas cinematográficos do Rio. Assim, será possível situá-los em ^ suas obras, seus contextos e seus meios de proڤิ dução. Como opção metodológica, em coerên$\underset{\mathcal{D}}{\sim}$ cia com as fontes, as trajetórias descritas foram cesa. Dessa forma, o crítico alçava à categoria de "autor" o cineasta que compreendesse uma obra a partir de similitudes temáticas. À concepção de autoria cinematográfica, a crítica brasileira associou posições não apenas estéticas, mas também sociais, políticas e ideológicas. O espaço para a reflexão dos críticos era, sobretudo, os periódicos, uma vez que um caderno ou suplemento dedicava-se a um filme, por exemplo. Uma das transformações sofridas pelo campo ao longo das últimas décadas se deu justamente na perda desse espaço, hoje dedicado aos "espetáculos" em geral. A crítica, com isso, migrou para a academia e para a Internet. $^{7}$

Na presente pesquisa, foi possível verificar um número expressivamente maior de críticas a Rio, 40 graus e de matérias sobre Nelson Pereira dos Santos, em detrimento do primeiro cineasta. Dos documentos, ainda é possível constatar que, mesmo depois da morte de Watson Macedo, em 1981, o diretor não conta com dados quantitativos significativos, seja na imprensa em geral, seja no meio acadêmico. Tal fato mostra, a princípio, a importância sociológica do problema, uma vez que a ausência de documentação se torna, em si, um dado analítico, configurando indícios variados. Colocado o desafio, começarei pelo "rei da chanchada".

\section{A CAPITAL DA ALEGRIA: Watson Macedo e a recepção de Rio Fantasia}

Quem foi Watson Macedo e como foi descrito por críticos (e entre seus pares) no campo do cinema brasileiro? Qual a importância do cineasta? Ele foi, de fato, um "cronista" da cidade? Como representou a capital? Vejamos algumas respostas por meio de documentos críticos e jornalísticos.

Em texto publicado no Correio da $\mathrm{Ma}$ nhã, de 18 de julho de 1971, Angela Belmiro

${ }^{7}$ Sobre um mapeamento sociológico do campo da crítica, ver Altmann (2016). Para uma discussão ampliada sobre a "política dos autores", ver Bernardet (1994). 
Fontes escreve a seguinte trajetória do diretor:

Watson Macedo não tem orgulho dos filmes que fez até hoje, mas um direito ele se reserva: '- Muito antes do Chacrinha, eu pensava em me comunicar com o público, em fazer filmes que as pessoas entendessem e gostassem'. Sem nunca ter lido um livro sobre cinema, ele conseguiu sair do interior do Estado e vir ao Rio fazer todo mundo rir com a célebre fórmula dos filmes de carnaval, briga, mulher e samba, que, durante as décadas de 40 e 50, dirigiu para a Atlântida. ${ }^{8}$ (Fontes, Correio da Manhã, 18/07/1971, grifo meu)

A descrição segue a contar o sonho de Macedo em se tornar cineasta e sua verve cinefílica ("ia ao cinema todo dia e sabia os nomes dos diretores”), até conhecer a atriz, diretora e produtora Carmen Santos, no estúdio de cinema Brasil Vita Filmes.

Naquela época, a moda era ser técnico de som, o cinema ainda deslumbrado com o novo recurso, ela ofereceu o lugar. Watson não quis, mas ficou pelo estúdio e acabou como assistente de direção do filme Inconfidência Mineira, dirigido pela própria Carmen [...] [Então] foi para a Atlântida, começar tudo outra vez. Foi assistente de José Carlos Burle e Moacir Fenelon, e montador, com fitas em volta do pescoço, esperando a hora de fazer o drama. E a chance do primeiro filme veio em termos de gargalhadas. '- Eu tinha horror a comédia. Foi preciso uma semana para me convencerem e estrear como diretor dessa maneira'. E o filme saiu em 45, com Oscarito, Grande Otelo, Mary Gonçalves e os clássicos números musicais com Linda e Dircinha Batista, Emilinha Borba, Silvio Caldas, Ciro Monteiro e Anjos do Inferno. O título era o que ele sentia. 'Não adianta chorar'. Foi um sucesso muito maior que o anterior, e a Atlântida prosseguiu no esquema dos filmes carnavalescos. Com Esse mundo é um pandeiro, o sucesso estava garantido. Ficou várias semanas em cartaz, numa época em que só filmes estrangeiros tinham esse privilégio. Os críticos de cinema começaram a malhar, e as filas cresciam nas portas dos cinemas. Watson ganhou um título que detesta

${ }^{8}$ Sobre a Atlântida: "Empresa produtora fundada em 1941, no Rio de Janeiro, pelos irmãos José Carlos Burle e Paulo Burle, juntamente com Moacir Fenelon, Arnaldo Farias e Alinor Azevedo, com apoio do Jornal do Brasil. Na sede do jornal é montado o estúdio de pequeno porte [...] Em 1966 une-se a vários produtores brasileiros na realização de grande quantidade de filmes populares dos mais variados gêneros, feitos sempre em locações. No ano de 1983, a empresa deixa de produzir definitivamente" (Miranda, 2000).
'O rei das chanchada' [...] Por volta de 1960, a velha fórmula entrou em declínio, com o aparecimento do Cinema Novo e a concorrência da televisão, e Watson foi ficando esquecido e magoado com a imprensa. O Cinema Novo não tinha pra ele a mesma força de comunicação, não solidificou uma indústria e não atraía público, pelo menos, o mesmo tipo de público das chanchadas. As preocupações agora eram outras, a realidade brasileira com suas implicações sociais, políticas e econômicas substituía a fantasia que Watson criava. Aí ele parou, deu lugar aos que tinham começado com ele como assistentes, Anselmo Duarte e Roberto Farias, e tantos outros técnicos (Fontes, Correio da Manhã, 18/07/1971, grifo meu).

Embora raras as fontes sobre Macedo antes e depois de sua morte, são numericamente relevantes as publicadas em 1981, como a do Jornal do Brasil, intitulada "Watson Macedo segundo Eliana: um mago do cinema que levava alegria ao povo":

Não é fácil falar sobre esse homem singular que foi Watson Macedo [...] Pode-se, sem exagero, afirmar que ele foi um mago em sua profissão [...] Seus filmes foram todos grandes êxitos de bilheteria e que levavam ao povo aquela alegria que o espectador espera ao adquirir seu ingresso; ao contrário do que ocorre hoje, quando as famílias deixam as casas de espetáculos envergonhadas com os filmes pornográficos a que assistiram [...] Era autodidata e acabou sendo considerado o professor da maioria dos que hoje produzem filmes rotulados de diretores (às vezes com aspas) ${ }^{9}$ (Eliana, Jornal do Brasil, 12/04/1981, grifo meu).

O trecho escrito pela sobrinha do diretor e estrela de seus filmes indica uma repulsa à pornochanchada e reforça certo "didatismo" do cineasta. Esta última idéia sugere que os saberes do artista e sua qualificação cultural se dariam mais em termos "amadores" do que

${ }^{9}$ Nessa mesma página especial, há um texto intitulado "A chanchada", assinado pelo crítico José Carlos Avellar, do qual copio o seguinte trecho: "Comédias especiais feitas especialmente no período que vai do começo da década de 40 até a metade da década de 50, para exibição nos meses que precediam o carnaval, as chanchadas ocuparam um espaço aberto entre o rádio brasileiro e o cinema americano [... Foi nesse espaço que Watson Macedo atuou como diretor de filmes entre a chanchada e o filme sério, num tempo em que ainda não existia a televisão para fazer o rádio sofisticado ou a versão direta do cinema americano através da dublagem. Num tempo em que apenas os dois filmes de Nelson Pereira dos Santos anunciavam o que seria mais tarde o Cinema Novo". 
propriamente técnicos ou expertos. Para Eliana e para os jornalistas a seguir indicados, tal fato não apresenta obstáculos. As matérias transcritas em seguida conferem teor de enaltecimento e "paixão" póstuma em relação à figura de Macedo e sua cinematografia. O artigo intitulado "Morre o cineasta Watson Macedo", publicado na Folha de S. Paulo, assim descreve o diretor:

\begin{abstract}
O cinema brasileiro teve em Watson Macedo uma das mais importantes personalidades, um nome ligado intimamente ao que a chanchada produziu de melhor nos anos 40 e 50, um período que poderíamos classificar como dos mais férteis em termos de comunicação do cinema nacional com seu público [...] Macedo, assim, foi um dos responsáveis pelo esforço de criar, através de um gênero, uma indústria de cinema genuinamente nacional, o que foi feito na Atlântida, responsável pela maioria das chanchadas daquelas duas décadas [...] A relevância [de sua obra] está menos no número de filmes que realizou e mais na exploração de um gênero que refletia um povo brincalhão, irônico e feliz, que brincava no carnaval, brigava nos bares, namorava no Pão de Açúcar, ria sem preconceitos e tinha esperança no futuro (O.L.F., 09/04/1981, grifo meu).
\end{abstract}

Além do reconhecimento de Macedo e sua obra, o trecho assinala o que nela continha: a construção de um tipo carioca a viver num cenário natural e idílico, similar às pinturas do século XIX. Tais temas persistem na matéria publicada em $O$ Globo, de 9 de abril de 1981, intitulada "Watson Macedo (1918-1981). : ¿ tico José Carlos Monteiro escreve:

Watson Macedo era praticamente desconhecido pelas novas gerações. Mas os espectadores das décadas de 40 e 50 o reconheciam, sem dúvida, como um de nossos maiores autores de comédias musicais. A ele, o cinema carioca deve clássicos como $O$ cinema é um pandeiro, Carnaval no fogo e Rio fantasia. Embora nem sempre devidamente reconhecida pela crítica, sua contribuição é inestimável. Além de consolidar um gênero (o musical carnavalesco), Watson ajudou a sustentar nossa indústria cinematográfica, antes do advento do Cinema Novo e da Embrafilme [...] Com a explosão cinemanovista, o veterano comediógrafo busca novas formas. O turístico Rio, verão e amor é seu último trabalho para o cinema. E não é certamente o que gostaria de ter feito para encerrar uma trajetória das mais criteriosas e profundas. (Monteiro, 1981, grifo meu).
Monteiro aponta certa indiferença da crítica, que subestimava ou não autenticava a "contribuição inestimável" de Macedo por ter consolidado um gênero e sustentado uma indústria eminentemente brasileira. O texto novamente dá indícios de seus cenários a revelarem uma cidade "turística e carnavalesca", portanto, "alegre e bonita". Finalmente, publicado no jornal O povo (Fortaleza, em 26 de abril de 1981), a matéria assinada por Aramis Arão reitera a biografia do cineasta, trazendo, contudo, novos elementos melhor analisados de um ponto de vista sócio-histórico:

Morreu Watson Macedo. Um legítimo cineasta brasileiro que institucionalizou a chanchada musical-carnavalesca, com toda aquela pureza do encanto juvenil, da jovialidade adulta, da espontaneidade, da gíria carioca, do orgulho de ser bairrista e cantar e decantar a Cidade Maravilhosa [...] Assistir a filmes musicais carnavalescos foi a maior alegria do brasileiro, no período que vai de Getúlio até Juscelino Kubitschek. Neste período de início de riqueza e paradoxalmente de miséria, frutificou uma rendosa equipe de produtores e cineastas que chegaram à seguinte conclusão: se não temos o suficiente gabarito para realizar superproduções, por que não contarmos toda a alma aberta do brasileiro de carnaval, e de escolas de samba, de Tijuca, Flamengo e Botafogo, surgindo a barca da Cantareira, unindo Rio e Niterói, e mostrar com quantos paus se faz uma comédia bem brasileira, às vezes sem nexo, sem sentido? Se, porventura, de longe lembrem alguns 'gags' de filmes americanos, [os filmes] permaneceram fiéis às raízes nacionais (Arão, 1981, grifo meu).

Neste último fragmento, é confirmada a presença, nos filmes de Macedo, da "cidade maravilhosa" e suas texturas culturais. As escolas de samba, assim como determinados bairros, configurariam o que seria "bem carioca", a despeito de certo pastiche norte-americano. Dos cinco textos, destaco uma condecoração póstuma de um "legítimo cineasta", ignorado pela crítica por representar um estilo de cinema "popular", posteriormente atestado por sua "pureza" e "alegria". Tais características compõem a chanchada de Macedo assim descrita em livreto do Museu da Imagem e do Som, datado de março de 1975: 
[...] um gênero de cinema brasileiríssimo, espontâneo, nascido do acaso e que soube não só transportar integralmente em sua temática o espírito nacional em sua irreverência, como também criar uma nova linguagem cinematográfica primária artesanalmente, mas bastante comunicativa. Estamos desencavando as chanchadas, outrora desprezadas pela elite cinéfila e consideradas 'subprodutos destinados ao consumo do povo subdesenvolvido'. A série Atlântida, fase de sofisticação do gênero, é a mais importante como fenômeno de comunicação popular e registro do 'kitsch' brasileiro. Watson Macedo é o pai da chanchada da Atlântida. (Museu da Imagem e do Som, 1975, grifo meu).

Até aqui, todas as leituras, incluindo esta última, parecem dialogar com o tom dúbio da primeira de duas únicas críticas encontradas sobre o filme de Macedo rodado em $1957 .{ }^{10}$ Nela se constata um reconhecimento, mas também um caráter negativo em relação a Rio fantasia. Esse último perfil talvez explique o ínfimo número de análises publicadas em meios de comunicação da época.

Em 12 de fevereiro de 1957, em Cine-Repórter, Aguinaldo Azevedo Marques publica a seguinte análise do filme:

Watson Macedo sempre procurou dar um padrão elevado para suas produções, dispensando-lhes um apurado cuidado técnico e não medindo despesas para suas realizações. Aqui, ainda não acertando com o argumento, consegue ser feliz, apresentando uma história agradável como veículo para uma série de números musicais, alguns sem razão, outros, porém, bem cuidados e até mesmo originais (é o caso do número de João Dias - completamente ridículo - e, por exemplo, o número de Eliana e mais o Trio Irakitan, nas praias de Copacabana, onde apresentou um cenário dos mais bem cuidados). No elenco, temos Eliana, que é realmente uma vocação para esse tipo de fitas. O Trio Irakitan, que fez sua estreia no cinema brasileiro, um galã apagado, além de uma equipe cômica realmente engraçada, tendo à frente Zezé Macedo, Madame Lou, Catalano e outros. Dos números musicais dos convidados, o de Angela Maria nos pareceu o menos ruim. Rio fantasia é mais um esforço do cinema brasileiro para atingir um padrão maior de produção e, como tal, deverá merecer

${ }^{10}$ Do escasso material sobre Rio Fantasia, além das duas críticas encontradas, publicadas na ocasião de sua estreia, destaco o trabalho de Dias (2010). todo nosso apoio. Além disso, é filme comercial e como tal será sucesso certo de bilheteria. (Marques, 1957, grifo meu).

O enunciado aparentemente hesitante e o "apoio" de Marques a Rio fantasia difere substancialmente de uma curta e enfática nota assinada por Antonio Moniz Vianna, publicada um mês depois, no $5^{\circ}$ Caderno do Correio da Manhã:

Oito-por-um. Rio fantasia. O chamado cinema nacional goza de todas as vantagens: exibição obrigatória, preços iguais aos dos filmes estrangeiros fotografados em Cinemascope e coloridos, o analfabetismo de $65 \%$ da população, a omissão da Censura (que não vê a pornografia e distribui a torto e a direito o certificado de 'boa qualidade'). Assim, tão protegido, só poderia mesmo produzir indecências como este Rio fantasia (Moniz Vianna, Correio da Manhã, 10/03/1957, grifo meu).

Contrariamente aos textos sobre Watson Macedo, veiculados na ocasião de sua morte, em ambas as críticas a Rio fantasia não se encontram aspectos referentes à capital, suas características e cultura. A primeira leitura se encerra na própria análise fílmica, já que o crítico se limita a descrever os números musicais, os artistas e a fotografia, além de defender a fórmula duplamente popular do filme: tanto no que representa quanto no público que atinge. De maneira oposta, a nota de Moniz Vianna não analisa a fita, fazendo uma espécie de condenação à sua própria existência propiciada pela lei "oito-por-um". ${ }^{11}$ O registro outorga certa superioridade técnica do cinema estrangeiro, sugere uma inferioridade qualitativa do público brasileiro (de maioria analfabeta) e denuncia a "omissão da Censura" em relação ao filme - fatos que teriam consentido obras de cunho supostamente menor, como a referida.

Dos documentos aqui expostos e das pistas sobre o Rio capital e seu contexto sócio-histórico, é possível extrair o seguinte diagnóstico: Watson Macedo, representante

${ }^{11}$ Em diálogo com o lema "todo cinema brasileiro deve ser visto", proposto pela revista carioca Cinearte, fundada em 1926, o governo de Getúlio Vargas, em 1951, criou a “"“cota de tela" chamada" "oito-por-um", cujo objetivo era exibir um filme brasileiro para cada oito estrangeiros. 
da chanchada, que ajudou a sustentar durante quase duas décadas a indústria cinematográfica nacional, produziu obras "indecentes", às vezes sem nexo, mas que, por sua vez, exaltavam a pureza juvenil e a gíria carioca, cantando as alegrias da cidade e seus cartões-postais para um público composto por analfabetos.

Com base nessa recepção, poderíamos rastrear uma nova cartografia da "cidade-capital” de meados do século XX, que reitera certa paisagem idílica e romântica das pinturas antecedentes, entretanto num contexto social já alterado, a compreender o subdesenvolvimento e a não civilização vistos pela crítica nas imagens "pornográficas" e no povo inculto. Tais leituras apresentam certa coerência com a interpretação de Paulo Emílio Sales Gomes sobre nosso "subdesenvolvimento”. Segundo o crítico,

o fenômeno cinematográfico que se desenvolveu no Rio de Janeiro a partir dos anos quarenta é um marco. A produção ininterrupta durante cerca de vinte anos de filmes musicais e de chanchada, ou a combinação de ambos, se processou desvinculada do gosto do ocupante e contrária ao interesse estrangeiro. O público plebeu e juvenil que garantiu o sucesso dessas fitas encontrava nelas, misturados e rejuvenescidos, modelos de espetáculo que possuem parentesco em todo o Ocidente mas que emanam diretamente de um fundo brasileiro constituído e tenaz em sua permanência. A esses valores relativamente estáveis os filmes acrescentavam a contribui-

\section{A CAPITAL NEORREALISTA: Nelson Pereira dos Santos e a recepção de Rio, $\mathbf{4 0}$ graus}

Dos volumosos textos sobre Nelson Pereira dos Santos publicados nos meios de comunicação (sem contar livros, catálogos de mostras, entrevistas, folhetos de cineclubes, pesquisas ou teses acadêmicas etc. - aqui não analisados ${ }^{12}$ ) e das inúmeras críticas a Rio, 40 graus, veiculadas em jornais de ampla circulação e em publicações mais restritas, privilegiei as das décadas de 1950 e 1960 - mais próximas ao lançamento do filme. Não descartei, contudo, documentos de décadas posteriores que comprovam uma regularidade contínua a revalidar certo olhar. Do cotejo entre as matérias sobre este cineasta e Watson Macedo, entre as críticas a ambas as películas e suas diferenças quantitativas e qualitativas, levanto a seguinte pergunta: por que o número de escritos encontrados sobre Nelson Pereira dos Santos e seu filme é incomparavelmente maior ao de Watson Macedo e Rio fantasia? ${ }^{13}$

Com a questão em mente, primeiramente, analisarei como foi traçada a biografia de Nelson Pereira pelos grandes meios.

"Cineasta de formação materialista, poeta do homem e de seus dramas, aberto ao mundo e suas angústias, Nelson Pereira dos

${ }^{12}$ Dentre os quais, destaco: Salem (1996), Fabris (1994) e Papa (2005). Reproduzo ainda o seguinte texto do Glauber Rocha (crítico) sobre o cineasta: "O autor no cinema brasileiro se define em Nelson Pereira dos Santos. [Ele] realizou, em Rio, 40 graus, o primeiro filme brasileiro verdadeiramente engajado. O adjetivo é válido e significa, há dez anos passados, uma tomada de posição corajosa, solitária e consequente. A censura investiu furiosamente: não era um filme para a burguesia, porque a burguesia só aplaude e premia filmes sociais quando eles são evasivos. Rio, 40 graus era um filme popular, mas não era populista; não denunciava o povo às classes dirigentes, mas revelava o povo ao povo [...] Nelson Pereira dos Santos é a mais fértil, madura e corajosa mentalidade do cinema brasileiro. Um dos intelectuais mais sérios de sua geração, consciente do seu papel histórico.” (Rocha, 2003, p. 104-110).

13 Em livreto do Centro de Estudos Cinematográficos de Minas Gerais, publicado em agosto de 1960, em texto assinado quatro anos antes, Cyro Siqueira analisa tal questão. Segundo o crítico, "Rio, 40 graus é um filme honesto e inteligente. Honesto principalmente quando foge dos quadros habituais do cinema nacional, recusando-se ao 'show' radiofônico ou à chanchada teatral que têm vivido os 'cineastas' da terra. É inteligente quando ambienta ao seu caso específico o processo narrativo visivelmente inspirado no neorrealismo italiano". 
Santos, como Graciliano Ramos, se move mais a contento no interior luminoso do homem bravio" (Silva, Jornal do Comércio, 28/07/1968). A frase que inicia a matéria intitulada "Raízes de um cineasta”, no Jornal do Comércio, encontra ecos em outros textos, como o da revista Veja, de janeiro de 1969, que, abaixo da foto do cineasta, estampou a seguinte descrição: "Um sol de 40 graus brilhava sobre uma velha câmera no dia em que o novo cinema brasileiro nasceu. O pai, Nelson Pereira dos Santos, é agora o seu papa”. Prossegue o texto:

No princípio era o caos: a chanchada representava todo o cinema brasileiro [...] Nesse confuso princípio, em 1955, Nelson Pereira dos Santos lança a pedra fundamental do moderno cinema brasileiro, com Rio, 40 graus [...] Era uma revolução, mas o caos persistia: o país vivia dias agitados e o chefe da polícia do então Distrito Federal proibiu o filme por motivos políticos e ideológicos. O verão de 1969 é bem mais claro [...] Quando fala de jornal e de cinema, Nelson cita as suas duas profissões. Ele foi redator do extinto Diário Carioca (o único jornal que defendeu Rio, 40 graus na época) e do Jornal do Brasil, até 1965 [...] De 1955 para cá, além de vários filmes curtos, ele montou Barravento, o primeiro filme de Glauber Rocha, e fez sete longas-metragens, alternando seus temas entre a paisagem urbana (Rio, 40 graus, Rio, Zona Norte, Boca de ouro e El justicero) e a rural (Mandacaru Vermelho e Vidas secas) (Revista Veja, 1969, grifo meu).

"Liderança do moderno cinema brasileiro" - assim Nelson Pereira é identificado no Diário Carioca, em matéria que compreende um "debate construtivo" realizado entre cineastas (dentre os quais, Alex Viany, Roberto Farias e o próprio Nelson): "O tom geral dos depoimentos referiu-se à necessidade de ser fixada uma temática nacional que reflita a autenticidade do Brasil e sua gente." (G. \& R. Santos Pereira, 11/09/1960, grifo meu).

Na década seguinte, o texto publicado em O Jornal apresenta o seguinte perfil do cineasta:

Chamado de "o papa do Cinema Novo brasileiro", [N.P.S.] indiscutivelmente impõe-se como um dos mais importantes cineastas da História de nosso cinema, junto ao veterano Humberto Mauro e ao contemporâneo Glauber Rocha. No plano da investigação estética fílmica, situa-se hoje ao lado dos gran- des realizadores internacionais. Como ser humano e Homem na Sociedade, as suas posições coincidem com as proposições humanistas de sua obra, ambos fundamente engajados na realidade de nosso tempo, refletindo com consciência, arte e sociedade, as condições gerais que o status lega ao cotidiano histórico. (Lopes, O Jornal, 11/06/1973, grifo meu).

Finalmente, na revista Filme Cultura, no dossiê sobre Nelson Pereira, de 1970, José Carlos Monteiro desse modo narra a sua trajetória:

Houve quem considerasse, ao tempo de Rio, 40 graus, o equivalente brasileiro do grego Michael Cacoyannis, do espanhol Juan Antonio Bardem e/ ou do indiano Satyajit Ray, tidos como os modelos mais expressivos do cineasta novo, humanista, preocupado em participar da transformação do mundo, através da câmera de filmar, ou da ação política. Pela lucidez crítica, consciência profissional e coerência artística, Nelson Pereira dos Santos poderia ser apontado como versão nacional daqueles diretores [...] A árdua trajetória que percorreu até agora reflete um longo empenho no sentido de transfundir uma posição teórica ('Quero mostrar, sem retoques, sem mistificações, ao Brasil e ao mundo, que nosso povo existe') para uma 'práxis' cinematográfica ('Procurei fazer filmes que reflitam e resguardem a tradição cultural brasileira') [...] Antes de Nelson, praticamente inexistia realismo nos filmes brasileiros. Quando ele estreou, em 1954/55, a chanchada estava no auge, a realidade carioca e nacional somente aparecia na tela sob o prisma deformante dos musicarnavalescos da Atlântida e dos melodramas cosmopolitas da Vera Cruz. [Assim, N.P.S.] empenhou-se na busca de uma linguagem original adaptada à nossa inspiração artística e à nossa cultura. (J.C.M., Filme Cultura, 11/1970, grifo meu).

Tais fragmentos oferecem um retrato de Nelson Pereira dos Santos como um cineasta intelectual, engajado politicamente na transformação de seu meio social, "autor" de imagens "autênticas" da identidade carioca (e também brasileira), já que conhecedor profundo da realidade de seu país. Sua estética, realista e original, refletiria o povo em perspectiva humanista. Longe de ser diletante, o artista é teórico, técnico e, igualmente a grandes nomes estrangeiros, apto a traduzir a nação, unindo arte e sociedade, teoria e práxis.

Se as matérias sobre Nelson Pereira 
apresentam concordância em seu conteúdo, elas se diferem das críticas a Rio, 40 graus publicadas logo após seu lançamento, uma vez que o olhar do campo sobre o filme não confere unanimidade. Por outro lado, observa-se que, nas décadas subsequentes e até hoje, tanto o diretor quanto Rio, 40 graus são alçados a uma categoria "alta", cuja "aura” teria instituído uma "verdadeira" imagem da cidade (e sua identidade), em detrimento das chanchadas e outros gêneros do período.

As críticas selecionadas e expostas a seguir elucidam o argumento. Antes de abordá-las vale lembrar que grande parte menciona a informação sobre a proibição do filme pela polícia na época. O caso não será aqui aprofundado, embora sejam citados documentos, como o publicado em 14 de dezembro de1955, intitulado "Incompetente o tribunal para conhecer o mandado de segurança impetrado a favor da exibição do filme - a decisão, ontem, da 5a . Câmara Cível": ${ }^{14}$

Com a sala repleta de artistas, jornalistas, fotógrafos e curiosos, reuniu-se ontem a $5^{\text {a }}$ Câmara Cível do Tribunal de Justiça local a fim de proceder ao julgamento do mandado de segurança perpetrado por Nelson Pereira dos Santos contra ato do ex-chefe de polícia do D.F.S.P. que proibiu a exibição em território nacional do filme brasileiro Rio, 40 graus [...] No entender [do chefe de polícia, que é 'visceral¿ escreve a seguinte notícia em sua crítica intituक lada Rio, 40 graus:

A interdição de Rio, 40 graus determinada há meses pelo Coronel Menezes Cortes produziu dois efeitos de espécie contrária. Um deles, muito lisonjeiro para a equipe que realizou a fita, pois a publicidade espontânea que a medida de arbítrio provocou atraiu a atenção do país inteiro para o assunto e a bilheteria se beneficiou com as discussões travadas

${ }^{14}$ Sobre esse caso específico e a recepção do filme pelo campo cinematográfico brasileiro, ver Lapera (2015). a respeito. O outro efeito produzido, entretanto, foi quase inoportuno: o vigor das contestações ao ato do antigo chefe de polícia, desde a imprensa até o Poder Judiciário, prepararam a opinião pública para assistir a um milagre cinematográfico e Rio, 40 graus não foi tramado senão para resultar na crônica da cidade do Rio de Janeiro durante um dos dias mais característicos de sua personalidade multiforme, que é um domingo de verão. (Ottoni, Diário Carioca, S/D).

Registrado o acontecimento, copio trechos do material crítico, a começar pela resenha do próprio Ottoni, que segue no mesmo texto:

Adotando o único processo narrativo adequado ao tema, Rio, 40 graus escolheu o método mais difícil do discurso cinematográfico para contar uma história cuja trama resulta da coordenação orgânica de vários temas isolados [...] O morro, o bairro elegante, o Maracanã, e os pontos de atração turística estão intimamente ligados pelas situações dramáticas puramente sentimentais ou simplesmente pitorescas [...] Este filme, que retrata uma cidade tão contraditória em 24 horas, e que havia de extrair das berrantes contradições seus efeitos de choque e, ao mesmo tempo, a sua unidade, conseguiu a coordenação desses elementos pelo domínio de um ritmo linear quase impecável [...] [Quanto aos tipos], se o operário é o bom e o burguês negocista é o corrupto, isso quer dizer simplesmente que o diretor elegeu essas figuras, entre muitas, sem, contudo, insinuar que a burguesia inteira é corrupta e só os operários e a gente de condição humilde possuem virtudes. (Idem, grifo meu).

Esse trecho expõe a presença de paisagens do Rio e seus tipos representados através de um discurso hermético. Aqui, a cidade é lida como "contraditória", sendo seus habitantes não mais jovens, alegres e carnavalescos, mas pequenos vendedores de amendoim, operários e burgueses. Apresentando visão diferente, pelo menos quanto à ideologia da película, Ely Azeredo escreve duas críticas intituladas "Rio, 40 graus" e "Ainda Rio, 40 graus", publicadas nos dias 14 e 15 de março de 1956:

O panfletário antecedeu o cineasta na construção de Rio, 40 graus. A matéria prima era boa: a cidade e uma câmera esforçada em registrar, sem mediação 
literária, a paisagem humana. Havia também um punhado de boas intenções na equipe que se formou em regime cooperativo, procurando fugir ao círculo vicioso das chanchadas e dramalhões para cumprimento do "oito por um". Nelson Pereira dos Santos, o argumentista-diretor, mostra conhecer os filmes realistas italianos, demonstra desembaraço e habilidade ao retratar o dia a dia urbano e em lidar com o homem da rua. Sua vocação para o cinema ‘semidocumentário’ é inegável [...] É claro que o simples registro em cenários autênticos, com intérpretes não profissionais narrando "casos dolorosos da cidade”, não é realismo [...] Rio, 40 graus vive um contraste forçado e desnecessário entre pobres e afortunados, generalizando as altas virtudes morais das camadas populares, transformando em tarados ou caricaturas as personagens burguesas [...] O processo narrativo é dificílimo, pois não existe propriamente uma história [...] As qualidades do filme derivam apenas da já citada habilidade 'documentária' do diretor, principalmente quando aplicada às figuras do morro. Os pequenos vendedores de amendoim são os melhores atores e também os portadores do protesto mais eloquente do filme, enegrecendo teimosamente, com sua miséria e sua teimosia de viver, os pontos 'coquettes' da cidade [...] Relativamente à pobreza material da produção, Rio, 40 graus exibe um grande esforço da equipe técnica, principalmente no setor fotográfico. O fundo musical utiliza como tema principal o excelente "A voz do morro", de Zé Keti, que também faz o papel do negro amigo de Miro (Jece Valadão). (Azeredo, 1956, grifo meu).

Ambas as análises sustentam o adjetivo "difícil". Assim como Ottoni, Azeredo conferiu um grau de dificuldade à narrativa, que foge do "círculo vicioso das chanchadas". Os dois textos ainda trazem menções aos "cenários autênticos da cidade" e às duas classes que dividem os cariocas de então: a burguesia, para Azeredo, caricata, e o proletariado, para ambos, enaltecido.

A interpretação de certo modo desfavorável do segundo crítico encontra ressonância com a de Octavio Bonfim que, em março de 1956, colocou o tradicional Bonequinho d'O Globo dormindo no filme. $O$ fato parece curioso por revelar que nem sempre Rio, 40 graus contou com "bons olhos" da crítica periodista. Ademais, a análise a seguir pode corroborar a hipótese da distinção aqui aventada. Segundo o crítico:
Transformado num divisor de opiniões, Rio, 40 graus sofre os efeitos perniciosos de uma publicidade artificial. Recebido com efusão por certo grupo intelectualizado, o filme não vem agradando ao público em geral. O desapoio do povo não teria importância se resultasse da incompreensão proveniente do alto valor técnico e artístico da obra [...] Querem-Ihe atribuir posição importante no panorama cinematográfico brasileiro, representando uma experiência nova. Entretanto, não sabemos por que falar em novidade se o filme é decalcado em estilo importado. Num campo comparativo só não seria lícito estabelecê-las com as chanchadas carnavalescas que temos visto ultimamente, ou algumas comédias da pior categoria, que têm sido impingidas ao público, pois, em Rio, 40 graus, bem ou mal, há esforço realizador. Outrossim, não se pode deixar de focalizar o sentido intencionalmente negativo e faccioso da fita, tudo de acordo com os interesses do mencionado sectarismo ideológico que aniquila a escola neorrealista. (Bonfim, O Globo, 17/03/1956, grifo meu).

Essa recepção novamente faz menção à dificuldade estética do filme, que teria resultado num desagrado do público mais amplo - daí o caráter que parece distinguir o gosto "difícil" (do intelectual) do "fácil” (do espectador "analfabeto" e "subdesenvolvido"), por exemplo. A crítica de Bonfim reafirma certo sectarismo ideológico e avalia a escola neorrealista por um viés denunciativo, na medida em que o estilo "importado" teria feito com que o filme não fosse inteiramente "nacional". Ainda assim, para o crítico d'O Globo, não seria "lícito" comparar Rio, 40 graus às chanchadas carnavalescas ou comédias "da pior categoria".

Quanto às idéias de um cinema "nacional e autêntico", José Carlos Monteiro, em documento do Centro Cultural Cândido Mendes/Cinemateca do MAM, sobre Rio, 40 graus, escreve:

Realizado em 1955, Rio, 40 graus marca os primeiros passos do novo cinema brasileiro nas fronteiras de uma linguagem autenticamente nacional. Embora fortemente influenciado pelas lições neorrealistas, o filme mescla, em sua estrutura, elementos dramáticos e cômicos, melodramáticos e chanchadescos, tipicizados por um comportamento carioca dos personagens e por uma maneira de ver as situações e as coisas de forma legitimamente brasileira (Monteiro, $\mathrm{S} / \mathrm{D}$, grifo meu). 
A "autenticidade legitimamente brasileira” (e carioca) descrita por Monteiro é reafirmada em texto assinado por Maurice Capovilla, em que o cineasta explica que

o novo não derivava da imitação do neorrealismo italiano, mas sim do fato de ser uma fita realista ao nosso modo, no qual os personagens estão construídos com a determinação do seu meio. Eles falam como estamos acostumados a ouvir um homem falar, se vestem como realmente um carioca se veste e têm seus conflitos determinados pela realidade social circundante. (Capovilla, S/D, grifo meu).

Os dois fragmentos sugerem que, embora inspirado num movimento italiano, Nelson Pereira teria traduzido, numa "linguagem autenticamente brasileira”, o "verdadeiro" carioca, já que seus personagens são "iguais aos que vemos nas ruas".

Além do caráter estético, ideológico e autêntico reiterado por agentes da crítica e do campo cinematográfico como um todo, vale observar, não raras vezes, que a recepção de Rio, 40 graus é composta por julgamentos sobre o que é "bom" e "ruim", “culto" e "ingênuo". De forma a constatar como esse modo de pensar perdura no tempo, cito matéria assinada pelo cineasta e crítico Gustavo Dahl, no Caderno B do Jornal do Brasil, cinco décadas depois da realização do filme:

A eleição de Juscelino Kubitschek, em 1955, encerra de fato a República Velha que os tenentes e Getúlio começaram a demolir em 1922, 1924 e 1930. A superação da condição de colônia e sua conversão em metrópole assombravam o país desde a vinda de Dom João VI. Em 1955, este desejo recôndito e explícito de abandonar a dependência do mundo exterior e tornar-se produtor independente tomou conta do país. E fez-se Rio, 40 graus. A importância simbólica e emblemática do filme de Nelson Pereira dos Santos remanesce insuportavelmente jovem. Longe dos estúdios da Cinédia, da Atlântida ou da Vera Cruz, Rio, 40 graus confirma a máxima gramsciana formulada por Gianni Amico: "O primeiro conteúdo de um filme é o seu orçamento”. Nelson Pereira dos Santos consegue libertar o cinema brasileiro de sua ingenuidade popularesca. Rio, 40 graus traz um sentimento de verdade e liberdade do qual se nutre a noção de modernidade. (Dahl, 14/01/2005, grifo meu).
Na visão de Dahl, percebe-se a edificação de Rio, 40 graus e Nelson Pereira dos Santos como um filme e um cineasta de ruptura, que teriam libertado o cinema brasileiro da "ingenuidade popularesca" dos estúdios. Entende-se, portanto, que a proposta de Nelson Pereira parecia estar em conformidade com a de seus pares, intelectuais de esquerda, que prezavam por um cinema "pobre" - de baixos recursos - como denúncia do subdesenvolvimento moderno e livre da condição colonial.

Se críticas contemporâneas à estreia do filme apresentaram opiniões por vezes desfavoráveis, sua legitimidade para a posteridade parece se constituir nos discursos de certa intelligentsia que a reitera indefinidamente. Como mais um exemplo futuro, e de modo a pensar certo modus operandi do campo cinematográfico brasileiro, cito um texto publicado na Tribuna da Bahia, em 1995, sobre a comemoração dos 40 anos do filme, em que o cineasta Guido Araújo descreve seu testemunho:

No ano de 1954, quando em São Paulo fracassava o sonho hollywoodiano dos Estúdios Vera Cruz, no Rio de Janeiro um punhado de jovens idealistas, liderados por Nelson Pereira dos Santos, se juntou num projeto revolucionário e audacioso - realizar, praticamente sem recursos, um filme em que o próprio povo brasileiro fosse o principal protagonista. (Araújo, 05/06/1995, grifo meu).

Da mesma matéria, que trata de reconstituir a memória de Rio, 40 graus, consta a nota intitulada "Jorge Amado elogia crônica do cotidiano", com a seguinte informação:

Entre os inúmeros intelectuais que escreveram sobre Rio, 40 graus e sua proibição, estava Jorge Amado que publicou um importante artigo sobre o assunto na edição de 27 de setembro de 1955, na 'Imprensa Popular', do qual reproduzimos aqui parte do primeiro parágrafo: 'Tive ocasião de assistir a uma exibição de Rio, 40 graus. Eis aí um filme limpo, honesto, espécie de crônica cotidiana da cidade do Rio de Janeiro, com momentos de alta beleza e profunda poesia. O espectador não poderá mais esquecer o negrinho vendedor de amendoins com a sua lagartixa, único bem que ele possui, sua afeição maior, dona de todo o carinho desse pequeno órfão 
da cidade. Os conflitos inúmeros da cidade imensa, as tristezas e alegrias do povo são fixados pela câmera e, por vezes, uma onda de emoção sacode o espectador' (Tribuna da Bahia, 05/06/1995, grifo meu).

Da recepção aqui tratada, pode-se deduzir que cineastas e intelectuais "idealistas" envolvidos naquele momento histórico, ao preconizarem um "projeto revolucionário e audacioso", parecem ter conferido a si próprios, sob a "liderança" de Nelson Pereira, certa missão de protagonizar o "verdadeiro" povo brasileiro nas telas. ${ }^{15}$ Ao decretar que "o espectador não poderá mais esquecer o negrinho vendedor de amendoins", Jorge Amado e seus amigos cineastas teriam estipulado, ulteriormente, uma imagem carioca (e nacional) baseada num tipo social, num cenário e numa estética específica. Assim, contrariamente à imaginação do Rio idílico e alegre descrito nas matérias sobre Watson Macedo, a que parece predominar, devido à sanção crítica, é a capital pobre e complexa, cujo lócus (a favela) está à margem dos cartões-postais. Nesse cenário, estariam nossas "verdadeiras" raízes. Aqui, o imaginário pictórico do século anterior parece findar.

\section{SOBRE A "POSTERIDADE" E OS HORIZONTES DE EXPECTATIVA}

Entre a capital jovem, branca e alegre de Watson Macedo e a pobre, negra e conflituosa de Nelson Pereira, que, em certo sentido, predomina não só na crítica mas no próprio cinema brasileiro (levando-se em conta grande parte da produção contemporânea ${ }^{16}$ ), é possível estabelecer, em princípio, dois caminhos reflexivos sobre a imagem que permanece do Rio capital:

1) o primeiro estaria pautado na hipótese da

${ }^{15}$ Para um aprofundamento dessa discussão, ver Galvão e Bernardet (1983)

${ }^{16}$ Dessa produção, vale ressaltar filmes como Cidade de Deus (Fernando Meirelles e Kátia Lund, 2002); Tropa de Elite (José Padilha, 2007); Notícias de uma guerra particular (João Moreira Salles e Kátia Lund, 1998); Santa Marta - duas semanas no morro e Santo forte (Eduardo Coutinho, 1987 e 1999), entre outros. distinção, baseada na valorização, por parte de críticos e intelectuais, de uma linguagem "difícil” e engajada politicamente, a conter um projeto de transformação social. Aqui, teríamos como mais legítima (ou "verdadeira") a imagem do Rio de Janeiro de Nelson Pereira dos Santos, porque o discurso hegemônico de certo grupo assim teria chancelado;

2) o segundo caminho, que perpetua a mesma imagem de Rio, se encontra no fato de a favela, como território real, ter ultrapassado certa dimensão simbólica, conquistando autonomia de autorrepresentação ${ }^{17}$ (desnecessitando, assim, de porta-vozes de certa elite supostamente missionária).

Do segundo caminho, me limitarei a atentar à vasta produção de investigações, das quais ressalto estudos exemplares como os de Autran (2003), Barbosa (2006), Nagib (2003), Rossini (2003) e Xavier (2006a, 2006b), que se propõem a examinar a favela (e seus "graus de realismo") como um dos cenários prevalecentes do cinema brasileiro contemporâneo. Dentre tantas outras pesquisas sobre o tema, há referência quase unânime a Rio, 40 graus, visto como um filme de ruptura (estética e ideológica), a apresentar "o outro lado do cartão-postal do Rio de Janeiro" (Rossini, 2003, p. 30). Além do conjunto bibliográfico, atento para a importância da inserção dos próprios atores sociais de favelas no debate, já que, devido a mudanças sociopolíticas vivenciadas pelo país nos últimos anos, os mesmos vêm conquistando autonomia para apresentarem "autoimagens", com base em sua experiência e imaginação social, sempre situadas.

Quanto ao campo da crítica, que trabalha com a legitimação de autores, gêneros e linguagens, proponho a seguinte imaginação: e se, ao invés de chancelar Nelson Pereira e Rio, 40 graus, a crítica tivesse feito o oposto, reconhecido como "verdadeira" a imagem carioca da chanchada?

De modo a entender a autoridade do campo, já discutida em trabalhos anteriores, ${ }^{18}$ trato

17 Para uma análise do conceito, ver Gonçalves, Marques e Cardoso, (2012).

${ }^{18}$ Ver: Altmann (2008, 2016). 
de dialogar com o historiador Alcides Freire Ramos (2005), que, embora não utilize o conceito de "distinção", confere fundamentos em seu questionamento sobre a desvalorização da chanchada pelo campo da crítica (e também pelo cinematográfico e intelectual, de uma forma geral) que salvaguarda o realismo de Nelson Pereira dos Santos (e outros "autores" do cinema brasileiro). Em artigo que se propõe a questionar fundações de uma historiografia do cinema (à luz do trabalho de Jean-Claude Bernardet, de 2004), Ramos indica uma "hierarquização" presente nas páginas dos jornais e revistas, que "apontava para uma concepção teleológica de história, de acordo com a qual a virada dos anos 1950 para os 1960 representava a vitória do 'progresso"' (Ramos, 2005, p. 2). Ao enfatizar que "a chanchada era algo que não merecia ser valorizado segundo a ótica da esmagadora maioria dos contemporâneos que se debruçam sobre a produção cinematográfica do período" (Idem), Ramos destaca o vocabulário utilizado por críticos da época que, no momento de emitir juízos de valor estético, desqualificavam as comédias cariocas por meio de termos como "baixo nível", "humor chulo", "grosseria”, "primarismo", entre outros.

Numa acareação com as críticas aqui examinadas, verifica-se a legitimidade e a canonização de Rio, 40 graus e seu diretor justamente ^ nesse sentido. Enquanto o "autodidata" Watson స्. Macedo "nunca leu um livro sobre cinema”, o 凶ં "intelectual” Nelson Pereira traçou uma "árdua trajetória transfundindo uma posição teórica para a práxis cinematográfica”. Talvez por ter escolhido "o método mais difícil do discurso cinematográfico", Rio, 40 graus foi "recebido com efusão por certo grupo intelectualizado". Por seu lado, as chanchadas, "outrora desprezadas pela elite cinéfila”, foram consideradas pela mesma crítica como "subprodutos destinados ao consumo do povo subdesenvolvido".

Enquanto o gênero representado por Macedo "refletia um povo brincalhão, irônico e feliz, que brincava no carnaval, namorava no Pão de Açúcar, tinha esperança no futuro e orgulho de ser bairrista, cantando a Cida- de Maravilhosa”, o (neo)realismo de Nelson Pereira, com seus "pequenos vendedores de amendoim", traduziu uma "linguagem autenticamente nacional" e a "autenticidade do Brasil e sua gente". Assim, com um filme "limpo, honesto, espécie de crônica cotidiana da cidade do Rio de Janeiro", o cineasta conseguiu "libertar o cinema brasileiro de sua ingenuidade popularesca", representada por "filmes comerciais", com "sucesso de bilheteria".

Tais classificações me levam a problematizar dicotomias da recepção pautadas por preceitos como "cinema erudito" e "cinema popular", "arte pela arte" e "arte comercial”, a servirem como mecanismos rígidos de distinção. Ao tentar impor conceitos de arte e de artístico, a consciência estética fundada em formas distintivas se responsabiliza pela criação de coleções ou categorias. Ela se encarrega, portanto, de enquadrar a arte, prendendo-a a formalismos - uma consequência em desacordo com a concepção ampliada da hermenêutica.

Ao conferir certa "aura" à obra de Nelson Pereira, a crítica brasileira demonstra sintonia com um pensamento crítico pautado não só na canonização de autores, mas também na valorização de determinadas estéticas (baseadas em concepções políticas, sociais e conceituais). Ao defender posições estético-ideológicas, a crítica confere reconhecimento a cinemas e autores "eruditos", contrapondo-se a linguagens julgadas ingênuas, supostamente desprovidas de qualidade artística e intelectual. Nesse entendimento, a rejeição do superficial "conduz naturalmente à rejeição do que é fácil no sentido ético e estético, de tudo o que oferece prazeres imediatamente acessíveis e, por conseguinte, desacreditados como 'infantis' ou 'primitivos' (por oposição aos prazeres da arte legítima)" (Bourdieu, 2007, p. 449). Desse modo, a lógica que une a qualidade "difícil”, reiterada pelos críticos de Rio, 40 graus, à condição "intelectual" de Nelson Pereira certifica um autor que não faz cinema destinado às massas, pertencendo, portanto, a uma elite cultural que parece não fazer parte do "amplo público subdesenvolvido". 
Talvez por ter sido recepcionado mais exclusivamente com base nessa perspectiva, o cinema de Nelson Pereira dos Santos foi enquadrado pela crítica na esfera "culta", o que acabou por lhe conferir um sentido de permanência no campo cinematográfico. Nesse processo, constituiu-se um parâmetro para a divisibilidade do gosto que contrapõe o "puro" e "sublimado" ao "impuro" e "primitivo". Tal distinção, a compreender uma "estilização da vida”, nega certa espontaneidade popular "produtora de efeitos ligeiros, sedutores e fáceis, em função da valorização de uma linguagem bela, prazerosa, que deve ser cultivada como forma de erudição" (Bourdieu, 2007, p. 168).

Tal força discursiva, cuja atribuição de um valor cultural específico passa a sancionar determinado tipo de imagem de uma cidade (ou nação), acaba sendo lida como a oficial e vista como instância a estabelecer "julgamentos para a posteridade” (Bourdieu, 2002). Nesse sentido, considero importante repensar a crítica cinematográfica como domínio de autoridade cultural que, por meio de imposições simbólicas, valida normas, representações e autorias em nome de projetos particulares. Ao certificar e constantemente revalidar uma imagem específica do Rio de Janeiro, em detrimento de tantas outras, o campo se incumbe do papel de atribuir a esta representação um caráter único e longevo. Se uma das tarefas da sociologia é conferir análises iconoclastas a fenômenos supostamente determinantes, acredito ser possível ampliar horizontes de expectativa tanto em relação a categorias cinematográficas quanto a validades de sua recepção.

Recebido para publicação em 18 de abril de 2016 Aceito em 17 de outubro de 2017

\section{REFERÊNCIAS}

ALTMANN, E. A crítica segundo a crítica latino-americana Contemporânea: revista de sociologia da UFSCar, São Carlos, v. 6, n. 2, p. 431-446, jul./dez. 2016.

ALTMANN, E. Olhares da recepção, a crítica cinematográfica em dois tempos. Caderno CRH, Salvador, v. 21, n. 54, p. 611-622, set./dez. 2008.
AUTRAN, A. O popular no documentarismo brasileiro contemporâneo. Revista Olhar, São Carlos, ano 4, n. 7, p. 144-153, jul./dez. 2003.

ARAÚJO, V. de P. A bela época do cinema brasileiro. São Paulo: Perspectiva, 1976.

AZEVEDO, A. N. de. A capitalidade do Rio de Janeiro: um exercício de reflexão histórica". In: AZEVEDO, A. N. (Org.). Rio de Janeiro: capital e capitalidade. Rio de Janeiro: UERJ, 2002. p.

BARbOSA, A. Periferia, cinema e violência. Sexta Feira, São Paulo, v. 8, p. 205-211, 2006.

BERNARDET, J.-C. Historiografia clássica do cinema brasileiro: metodologia e pedagogia. São Paulo: Annablume, 2004

BERNARDET, J.-C. O autor no cinema: a política dos autores: França, Brasil anos 50 e 60. São Paulo: Brasiliense: Edusp, 1994.

BOURDIEU, P. A distinção: crítica social do julgamento. São Paulo: Edusp: Porto Alegre: Editora Zouk, 2007.

CARVALHO, A. M. F. M. de. A construção da imagem da Baía de Guanabara. In: MARTINS, C. (Cur.). A paisagem carioca. Rio de Janeiro: Museu de Arte Moderna, 2000. p. 32-55.

DIAS, R. de O. O olhar da chanchada sobre a cidade do Rio de Janeiro. Contemporâneos: revista de Artes e Humanidades, n. 6, p. 1-17, maio/out. 2010.

DIAS, R. de O. O Mundo como Chanchada: cinema e imaginário das classes populares na década de 50. Rio de Janeiro: Relume Dumará, 1993.

FABRIS, M. Nelson Pereira dos Santos: um olhar neorealista? São Paulo: Edusp, 1994.

GALVÃO, M. R.; BERNARDET, J.-C. O nacional e o popular na cultura brasileira: cinema. São Paulo: Brasiliense; Rio de Janeiro: Embrafilme, 1983.

GOMES, P. E. S. Cinema: trajetória no subdesenvolvimento. Rio de Janeiro: Paz e Terra, 1980

GONCALVES, M. A.; MARQUES, R.; CARDOSO, V. Z (Org.) Etnobiografia: subjetivação e etnografia. Rio de Janeiro: 7 Letras, 2012.

HEFFNER, H. Paisagem carioca no cinema brasileiro. In: Imaginários cariocas: a representacão do Rio no cinema. Rio de Janeiro: Caixa Cultural, 2015. p. 11-19.

MARTINS, C. "Apresentação". In: MARTINS, C. (Cur.). A paisagem carioca.Rio de Janeiro: Museu de Arte Moderna, 2000. p. 16-19.

KORNIS, M. Samba em Brasília: uma utopia conservadora dos anos 50. SIMPÓSIO NACIONAL DE HISTÓRIA, 22., 2003, João Pessoa. Anais... João Pessoa: ANPUH, 2003.

LAPERA, P. V. A. Rio, 40 graus, Rio, Zona Norte: apresentação do campo do cinema brasileiro. Matrizes, São Paulo, v. 9, n. 1, p. 177-197, jul./dez. 2015.

LOBO, J. C. Cultura nordestina, sociedade carioca (Representacões de migrantes nordestinos na chanchada,1952-1961). Sociedade e Cultura, v. 9, n. 1, p. 161-172, jan./jun. 2006.

MELO, L. A. R. Um candango na Belacap. Contracampo, [S.l.],[20--]. Disponível em <http://www.contracampo. com.br/80/dvdcandango.htm >. Acesso em: 2 mar. 2016.

MIRANDA, L. F. Atlântida. In: RAMOS, F.; MIRANDA, L. F. (Org.). Enciclopédia do cinema brasileiro. São Paulo: SENAC Editora, 2000. p.

MORETTIN, E. V. Dimensões históricas do documentário brasileiro no período do silencioso" In: MORETTIN, E.

V: NAPOLIITANO, M.; KORNIS, M. A. (Org Historia e documentário. Rio de Janeiro: Editora FGV, 2012. p. 
MORETTIN, E. V. Dimensões históricas do documentário brasileiro no período silencioso. Revista Brasileira de História, São Paulo, v. 25 , n. 49, p. 125-152, jan./jun. 2005.

MOTTA, M. Rio, cidade-capital. Rio de Janeiro: Jorge Zahar, 2004

NAGIB, L. A língua da bala: realismo e violência em Cidade de Deus. Novos Estudos CEBRAP, São Paulo, n. 67, p. 181-191, nov. 2003.

PAPA, D. (Org.) Nelson Pereira dos Santos: uma cinebiografia do Brasil. Rio de Janeiro: Onze do Sete, 2005.

PINTO, C. E. P. de Imaginar a cidade real: o Cinema Novo e a representação da modernidade urbana carioca na década de 1960. In: SIMPOSIO NACIONAL DE HISTORIA. 26. 2011, São Paulo. Anais... São Paulo: ANPUH, 2011.

RAMOS, A. F. Historiografia do cinema brasileiro diante das Fronteiras entre o trágico e o cômico: redescobrindo a 'chanchada'. Fênix: Revista de História e Estudos Culturais, [Uberlandia], v. 2, ano 2, n. 4, p. 1-15, out./dez. 2005.

ROCHA, G. Revisão Crítica do Cinema Brasileiro. São Paulo: Cosac Naify, 2003.

ROSSINI, M. de S. Favelas e favelados: a representação da marginalidade urbana no cinema brasileiro. Sessões do Imaginário, Porto Alegre, n. 10, p. 29-43, nov. 2003.

SALEM, H. Nelson Pereira dos Santos, o sonho possível do cinema brasileiro. Rio de Janeiro: Record, 1996.

SCHWARCZ, L. M.; STARLING, H. M. Brasil: uma biografia. São Paulo: Companhia das Letras, 2015.

SOUSA, J. I. M.; CATANI, A. M. A chanchada no cinema brasileiro. São Paulo: Brasiliense, 1983.

SOUZA, J. I. de M. Imagens do passado - São Paulo e Rio de Janeiro nos primórdios do cinema. São Paulo: SENAC Editora , 2004.

VIEIRA, J. L. A chanchada e o cinema carioca (1930-1955). In: RAMOS, F. (Org.). História do cinema brasileiro. São Paulo: Art Editora, 1987. p.

VIEIRA, J. L. Chanchada. In: RAMOS, F; MIRANDA, L. F. (Org.). Enciclopédia do cinema brasileiro. São Paulo: SENAC Editora, 2000.p.

XAVIER, I. Corrosão social, pragmatismo e ressentimento: vozes dissonantes no cinema brasileiro de resultados. Novos Estudos CEBRAP, São Paulo, n. 75, p. 139-155, jul. 2006a.

XAVIER, I. Da violência justiceira à violência ressentida. Ilha ๙े do Desterro, Florianópolis, n. 51, p. 55-68, jul./dez. 2006b.

\section{DOCUMENTOS PESQUISADOS}

กิ

ALMEIDA, C. H. de. O jubileu de um clássico. Jornal do ó Brasil, 14 jan. 2005. Caderno B,

2. ARÃO, A. Saudades de Watson Macedo. O Povo, Fortaleza, i. 26 abr. 1981.

$\infty$.

¿ ARAÚJO, G. Rio Quarenta Graus, 40 anos depois. Tribuna da Bahia, Salvador, 5/ jun. 1995.

$>$ AVELLAR, J. C. A chanchada. Jornal do Brasil, 12 abr. 1981.

oิ AZEREDO, E. Rio, 40 graus. 14 mar. 1956.

AZEREDO, E. Ainda Rio, 40 graus. 15 mar. 1956.

BARBOSA, M. "Integrados" e "Malandros" em Rio, 40 graus. Jornal do Comércio, Rio de Janeiro, 18 maio 1997.

BILHARINHO, G. Cineastas brasileiros: Nelson Pereira dos Santos. Correio Carioca, Rio de Janeiro, 1 fev. 1969.

BONFIM, O. Rio, 40 graus faz Bonequinho roncar. $O$ Globo, Rio de Janeiro, 17 mar. 1956.
C. M. M. A morte do "pai" das chanchadas: Macedo. Estado de São Paulo, São Paulo, 9 abr. 1981.

CAPOVILLA, M. Rio, 40 graus.

CARVALHO, I. Watson Macedo, o pioneiro do cinechanchada. O Estado, Florianópolis, 10 out. 1982.

CENTRO CULTURAL CANDIDO MENDES. Cinemateca do MAM. Rio, 40 graus.

CINECLUBE RUY GURRA. Rio, 40 graus, Campina Grande, Paraíba..

CINECLUBE MACUNAÍMA/ABI. Rio, 40 graus, $3 \mathrm{dez}$. 1977.

CLUBE DE CULTURA TRINDADE. Rio, 40 graus. Rio, Zona Norte. 4 ago. 1974.

DAHL, G. Um cinema novo era possível. Jornal do Brasil, 14 jan. 2005. Caderno B.

E.P. "Watson Macedo. O cinema brasileiro perdeu um mestre da comunicação com o público". A chanchada, do exorcismo à reabilitação. Jornal da Tarde, São Paulo, 9 abr. 1981.

Eliana. Um mago do cinema que levava alegria ao povo. Jornal do Brasil, 12 abr.1981.

FEDERACÃO DOS CINECLUBES DO RIO DE JANEIRO. Nelson Pereira dos Santos. Manifesto por um cinema popular, Rio de Janeiro,1975.

MARQUES, A. Rio Fantasia. Cine-Repórter, 12 jan. 1957.

MONTEIRO, J. C. Watson Macedo (1918-1981). A morte de um criador de alegrias: ele ensinou o público a gostar de cinema nacional. O Globo, Rio de Janeiro, 9 abr. 1981.

MONTEIRO, J. C. Nelson Pereira dos Santos. Dossiê Filme Cultura, 1970.

MUSEU DA IMAGEM E DO SOM. Cinearte MIS. Filmes de Watson Macedo, mar. 1975.

NELSON, fome de cinema. Veja, São Paulo, 1969.

O.L.F. Morre o cineasta Watson Macedo. A marca de um estilo na chanchada. Folha de São Paulo, São Paulo, 9 abr. 1981.

OTTONI, D. V. Rio, 40 graus, Diário Carioca.

SCHENKER, D. Volta a fazer 40 graus no Rio. Jornal do Comércio, Rio de Janeiro, 8 maio 1997.

PEREIRA, G. \& R. S. Um debate construtivo. Diário Carioca, Rio de Janeiro,1 set. 1960.

SILVA, Alb. Raízes de um cineasta. Jornal do comércio, Rio de Janeiro, 28 jul. 1968.

SIQUEIRA, C. Centro de Estudos Cinematográficos de Minas Gerais. Rio, 40 graus. Belo Horionte, 6 ago. 1960 [1956].

SUKMAN, H. Fita rebobina para onde tudo começou. $O$ Globo, Rio de Janeiro, 16 maio 1997.

VIANNA, M. Rio fantasia. Correio da Manhã, Rio de Janeiro, $5^{\circ}$. Caderno, 10 mar. 1957.

VIANY, A. Rio, 40 graus.

WATSON Macedo, um descobridor de talentos. Jornal do Brasil, 24 jun. 1972. Caderno B. 


\section{RIO THE CAPITAL AS IMAGINED BY FILM CRITICISM: the cases of Rio fantasia and Rio, 40 graus}

Eliska Altmann

This article seeks to investigate how Brazilian film critics imagined Rio de Janeiro, "the capital city". Through criticism of the movies Rio fantasia [Fantasy Rio] (1957), by Watson Macedo, and Rio, 40 graus [Rio Forty Degrees], by Nelson Pereira dos Santos, the article intends to understand how certain agents described and legitimized Rio, the federal capital at that time, while judging it perhaps for posterity.

Keywords: Rio de Janeiro. Capitality. Movie theater. Film criticism.

\section{RIO CAPITALE IMAGINEE PAR LA CRITIQUE CINEMATOGRAPHIQUE: les cas de Rio fantaisie et Rio, 40 degrés}

Eliska Altmann

Nous nous proposons de vérifier, dans cet article, comment Rio de Janeiro, “ville-capitale" a été imaginée par les critiques cinématographiques brésiliens. Sur la base des critiques concernant les films Rio fantasie (1957), de Watson Macedo et Rio, 40 degrés (1955), de Nelson Pereira dos Santos, nous essayons de comprendre comment la capitale fédérale de l'époque a été décrite et légitimée par les agents qui ont émis des jugements, destinés peutêtre à la postérité.

Mots-Clés: Rio De Janeiro. Capitalité. Cinéma. Critique de cinéma.

Eliska Altmann - Doutora em Sociologia pela UFRJ (PPGSA). Trabalha com temas relacionados a produção e recepção de bens culturais, movimentos de criação artística, representações, identidades e América Latina. Autora do livro O Brasil imaginado na América Latina: a crítica de filmes de Glauber Rocha e Walter Salles - Contra Capa/ Faperj, 2010. Idealizadora do projeto CineCríticos, cujo portal é dedicado à crítica de cinema na América Latina: www.cinecriticos.com.br. Organizadora da coleção Cinema em livro: Eduardo Coutinho visto por, editada pela 7Letras - 2017. 
